\title{
High-Risk Sexual Behaviour in Young People with Mental Health Disorders
}

Asiel Yair Adan Sanchez ${ }^{1,2}$, Elizabeth McMillan ${ }^{1,2}$, Amit Bhaduri ${ }^{1,2,3}$, Nancy Pehlivan ${ }^{3}$, Katherine Monson ${ }^{3}$, Paul Badcock ${ }^{1,2}$, Katherine Thompson ${ }^{1,2}$, Eoin Killackey $^{1,2}$, Andrew

Chanen $^{1,2,3}$, Brian O’Donoghue $e^{1,2,3}$

${ }^{1}$ Orygen, the National Centre of Excellence in Youth Mental Health, Melbourne,

Australia

${ }^{2}$ Centre for Youth Mental Health, University of Melbourne, Melbourne, Australia

${ }^{3}$ Orygen Youth Health, Parkville, Melbourne, Australia

\section{Corresponding Author:}

Brian O’Donoghue,

Orygen Youth Health,

35 Poplar Rd,

Parkville,

VIC 3052, Australia

Email: briannoelodonoghue@gmail.com

This is the author manuscript accepted for publication and has undergone full peer review but has not been through the copyediting, typesetting, pagination and proofreading process, which may lead to differences between this version and the Version of Record. Please cite this article as doi:

This article is protected by copyright. All rights reserved. 


\begin{abstract}
Objective

This study aimed to determine the prevalence of high-risk sexual behaviours, sequelae and associated factors in young people attending a youth mental health service.

Methods

The study design was a cross-sectional survey of 103 young people aged between 15-25 years carried out across four specialist mental health clinics. A questionnaire on the sexual health of secondary level students was adapted for this study. Mental health symptomatology was assessed through the Brief Psychiatric Rating Scale (BPRS).

Results

The mean age was 20.9 ( $\mathrm{SD} \pm 2.8$ ) years, with $50.5 \%$ being female, $41.7 \%$ male and $7.7 \%$ transgender. A total of 52.4\% (N=54) attended the psychosis (EPPIC) clinic; $15.6 \%$ $(\mathrm{N}=16)$ attended ultra-high risk for psychosis (PACE) clinic; 19.4\% $(\mathrm{N}=20)$ attended personality disorders (HYPE) clinic; and 12.6\% ( $\mathrm{N}=13)$ attended mood clinic (YMC). The mean BRPS score was 47.7 ( $\mathrm{SD} \pm 12.2$ ). A total of $77.7 \%$ of young people had previously been sexually active and of these, $37.5 \%$ did not use consistent contraception; $26.3 \%$ had been pregnant, of which $95.2 \%$ were unplanned. A total of $68.8 \%$ reported having been tested for sexually transmitted infections and $25.5 \%$ tested positive. The
\end{abstract}


severity of symptoms or clinical characteristics were not associated with engagement in high risk sexual behaviours.

\section{Conclusions}

These results indicate that young people with mental health disorders have high needs in regard to their sexual health, which could be addressed by incorporating sexual health referral pathways into early intervention services.

Keywords

Young people, mental health, sexual health, sexual risk 


\section{Introduction}

It has been well-established that adolescence is a period of increased risk for both mental health disorders and high risk sexual behaviours (Bennett and Bauman, 2000). In Australian populations, both the onset of mental health disorders and engagement in high-risk sexual behaviour peaks in adolescence and young adulthood (Milnes et al., 2011); however, the relationship between the two and its implication for clinical practice is not fully understood.

International studies suggest that young people with mental health disorders engage in the same type of high-risk sexual behaviour as their peers in the general population, but at a higher rate (Donenberg and Pao, 2005; Ramrakha et al., 2000). This includes a younger age at first sexual experience, increased sexual activity, a higher number of sexual partners and a higher incidence of transactional sex (Agardh et al., 2012; Brawner et al., 2012; Turner et al., 2011; Buffardi et al., 2008). These high-risk sexual behaviours have been reported across a range of mental health disorders, including depression, mania, borderline personality disorders, psychosis and substance dependence disorders (Chanen et al., 2007; Stewart et al., 2012; Brown et al., 2010). Furthermore, young people with multiple, concurrent mental health disorders engage in high-risk sexual behaviours at 
higher rates than young people with a single mental health disorder (Ramrakha et al., 2000).

In addition, young people with mental health disorders also report low levels of contraceptive and condom use, leading to a higher risk for sexually transmitted infections (STIs) (Lehrer et al., 2006; Shield et al., 2005; Stewart et al., 2012). General practice is a common setting for routine sexual health promotion and testing for young people in Australia (Booth et al., 2004). However, young people affected by mental health disorders are less likely to attend mainstream health services (Cummings and Melissa, 2012), indicating a need for the integration of sexual health services within mental health services.

This study aimed to determine (i) the prevalence of high-risk sexual behavior and associated sequelae within a cohort of young people attending a youth mental health service; and (ii) whether an association exists between symptomatology, a history of nonconsensual sex, substance abuse disorders, gender, sexual identity and the engagement of high-risk sexual behaviour. The findings will add to our understanding of the sexual health of young people with mental health disorders in Australia. We hypothesized that young people with more severe mental health symptoms would have a higher prevalence of high-risk sexual behaviour (increased sexual activity, inconsistent contraceptive use, 
increased frequency of drug use during sex) and their sequelae (increased prevalence of pregnancy and sexually transmitted infections). We also hypothesized that this high risk sexual behaviour would be associated with a history of non-consensual sex, substance abuse, gender identity and sexual identity.

\author{
Methods \\ Setting \\ The study took place at Orygen Youth Health $(\mathrm{OYH})$, the State Government funded \\ youth mental health service for young people residing in northwestern to western \\ metropolitan Melbourne, Australia. OYH operates across four streams of care: First \\ episode psychosis (Early Psychosis Prevention and Intervention Centre (EPPIC)) \\ (McGorry et al., 1996), ultra-high risk for psychosis (Personal Assessment and Crisis \\ Evaluation (PACE)) (Yung et al., 2007), borderline/severe personality disorder (Helping \\ Young People Early (HYPE)) (Chanen et al., 2014), and mood disorders (Youth Mood \\ Clinic (YMC))(Rice et al., 2017).
}

\title{
Participants - Inclusion and exclusion criteria
}

Young people were eligible to participate if they were aged between 15 and 25 and were a current client of OYH. Participants with insufficient fluency in English were not eligible to be included in the study. Participants were recruited from both the outpatient 
and inpatient settings. Members of the research team met with case-managers from each of the clinics to identify potential participants. Case-managers were asked to inform the client of the study and if they were agreeable, then a meeting was arranged between a member of the research team and the client. Prior to the meeting, participants were informed by their case manager that the study comprised of a questionnaire about their mental health and their sexual health.

\section{Study design}

The study design was a cross-sectional survey.

\section{Instruments and measures}

Items relating to sexual risk behaviour were adapted from an instrument developed by the Australian Research Centre in Sex, Health \& Society (ARCSHS) (Smith et al., 2009). These included age at first sexual experience, current sexual partners, drug use whilst having sex, condom and contraceptive use, history of sexually transmitted infections, and history of pregnancy. Age at first sexual experience was defined at age at which oral sex first occurred. Questions relating to pregnancy were also extended to participants whose sexual partner or partners had become pregnant. Further questions were developed to include experience of non-consensual and transactional sex. Participants had the option of answering these questions via self-report or by interview. 
The number of sexual partners was dichotomised to less $\leq 3$ in the last 12 months and e 3 in the last 12 months in accordance with previous research carried out on secondary school students (Smith et al., 2009). To facilitate analyses, gender was categorized into "male", "female" and "transgender and gender diverse". The latter included participants who were transgender, non-binary or not sure of their gender.

Mental health symptomatology was assessed using the Brief Psychiatric Rating Scale (BPRS), which has been validated in terms of reliability and sensitivity (Hedlund and Vieweg, 1980). The BPRS contains 24 items, which measure affective, anxiety and psychotic symptoms. BPRS scores have been correlated to Clinical Global Impression ratings as follows: 'Mildly ill' corresponded approximately to a total score of 31 ,'moderately ill' to a score of 41 , 'markedly ill' to a score of 53 , 'severely ill' to a score of 70 and 'extremely ill' to a score of 85 (Leucht et al., 2005). An audit tool was developed to obtain information from the participants' clinical file, including formal diagnoses given by the treating team and clinic allocation. Diagnoses were assigned by treating psychiatrist.

Statistical Analysis

This article is protected by copyright. All rights reserved. 
Data analysis was carried out in SPSSv22. Data were screened for inconsistencies and missing values. BPRS scores were normally distributed and therefore means and standard deviations are presented and ANOVA analysis was performed to determine if BPRS scores differed amongst the different clinics attended. In addition, Chi-square analyses were carried out between sexual behaviour and each of the following categories: gender, substance abuse, sexual identity and non-consensual sex. These had been identified as potential mediating factors for high-risk sexual behaviour (Schuster et al., 2013; Elkington et al., 2010; Shrier et al., 2001; Turner et al., 2011). Given the number of Ç analyses conducted as per Table 5, a Bonferonni correction was applied to maintain statistical significance equivalent to $\mathrm{p}=0.05$. Sixty Chi-square analyses were carried out, giving an equivalent $\mathrm{p}$-value of 0.0008 . As a result, only $\mathrm{p}$-values of $<0.0008$ were taken to be statistically significant. Standardized residuals (SR) are presented within the Chisquare analysis. In Table 4, thirteen t-tests were performed and therefore only p values of $<0.003$ were taken to be statistically significant.

\section{Ethical Approval}

Ethical approval was granted by The Human Research Ethics Committee at Melbourne Health. All participants provided written consent. Ethical approval was granted for young people aged between 15 to 17 years to be able to provide written consent for themselves, 
if they had decisional capacity. Participants were reimbursed \$20 for their time and travel costs.

\section{Results}

\section{Participant characteristics}

A total of 163 participants were approached and of these, 116 agreed to participate in the study and 103 completed the assessment. Response rates were similar across clinics, with 65.7\% $(\mathrm{N}=54)$ from EPPIC clinic, 69.6\% $(\mathrm{N}=16)$ from PACE clinic, 71.4\% $(\mathrm{N}=20)$ from HYPE clinic and $68.4 \%(\mathrm{~N}=13)$ from YMC. The mean age was $20.9(\mathrm{SD} \pm 2.8)$ years, with $50.5 \%(\mathrm{~N}=52)$ being female, $41.7 \%(\mathrm{~N}=43)$ male and $7.7 \%(\mathrm{~N}=8)$ transgender or gender diverse. In regard to sexual identity, 54.5\% (N=56) identified as heterosexual, $32 \%(\mathrm{~N}=33)$ identified as bisexual or pansexual, $4.9 \%(\mathrm{~N}=5)$ as homosexual, $7.7 \%(\mathrm{~N}=8)$ as unsure or other, and $1 \%(\mathrm{~N}=1)$ as asexual. The demographic and clinical characteristics of participants are presented in Table 1.

\section{Diagnoses and Symptomatology}

A total of $52.4 \%(\mathrm{~N}=54)$ attended the EPPIC clinic; $15.6 \%(\mathrm{~N}=16)$ attended the PACE clinic; $19.4 \%(\mathrm{~N}=20)$ attended the HYPE clinic; and 12.6\% $(\mathrm{N}=13)$ attended the YMC clinic. The mean BPRS score was $47.7(\mathrm{SD} \pm 12.2)$ and there was no statistically significant difference between severity of global psychiatric symptomatology across 
clinics $(\mathrm{F}=0.38 ; \mathrm{df}=3 ; \mathrm{p}=0.77)$. Information relating to the symptomatology and diagnoses of participants is presented in Table 2 .

\section{Sexual Behaviour}

The mean age at first sexual experience was $16.5(\mathrm{SD} \pm 1.9)$ years. A total of $77.7 \%,(\mathrm{~N}=$ $80)$ had been sexually active and $63.8 \%(\mathrm{~N}=51)$ had been sexually active within the last month. Within the last 12 months, $61.5 \%(\mathrm{~N}=48)$ had a regular sexual partner and $36.2 \%$ $(\mathrm{N}=29)$ had more than three partners. Detailed information on sexual behaviours are presented in Table 3 . Among the young people who had ever been sexually active, $48.8 \%$ $(\mathrm{N}=39)$ had talked about pregnancy with their previous sexual partner and $59.5 \%(\mathrm{~N}=47)$ had talked about condom use. However, 37.5\% $(\mathrm{N}=30)$ did not consistently use any form of contraception, $63.8 \%(\mathrm{~N}=51)$ did not use consistent barrier contraception and $62.5 \%$ $(\mathrm{N}=50)$ did not use consistent non-barrier contraception. Among young people who had been sexually active, $15.2 \%(\mathrm{~N}=12)$ used alcohol frequently during sex. The same proportion $(15.2 \%, \mathrm{~N}=12)$ used cannabis frequently and $8.9 \%(\mathrm{~N}=7)$ used amphetamines frequently during sex.

Sequelae - Sexually Transmitted Infections (STIS)

Of those who had been sexually active, $68.8 \%(\mathrm{~N}=55)$ of young people had been tested for an STI and 25.5\% (N=14) had a positive test for an STI. The commonest STI reported 
was chlamydia $(71.4 \%, \mathrm{~N}=10)$, followed by gonorrhoea $(14.3 \%, \mathrm{~N}=2)$ and genital warts $(14.3 \%, \mathrm{~N}=2)$.

\section{Sequelae - Pregnancy}

Of those who had been sexually active, $26.3 \%(\mathrm{~N}=21)$ had been pregnant (five pregnancies related to males whose partners had been pregnant) and 95.2\% (N=20) of those pregnancies were unplanned. Nearly half of the pregnancies ended in termination $(\mathrm{N}=9,45.0 \%)$, while six pregnancies ended in miscarriage and five resulted in a live birth.

\section{Associated Factors}

It was investigated whether a number of demographic and clinical factors were associated with high-risk sexual behaviours and the results of these analyses are presented in Table 4, Table 5 and in the supplementary tables. The severity of global psychiatric symptomatology (as measured by the BPRS) was not associated with sexual activity, drug use during sex, communication with sexual partners, contraceptive use, STIs or pregnancy. Furthermore, there were no associations between a history of non-consensual sex, co-morbid substance abuse, sexual or gender identity and high-risk sexual behaviours. 


\section{Discussion}

\section{Summary of findings}

Young people with a mental health disorder in this study had a high prevalence of highrisk sexual behaviours and their sequelae. These high-risk sexual behaviours were homogeneous across specialist clinics and psychiatric symptomatology. Additionally, there was a high incidence of pregnancy, STIs and inconsistent contraceptive use.

\section{Mental Health and Sexual Behaviour}

The results add to previous findings indicating inconsistent condom use in young people with first episode psychosis (Brown et al., 2010) and depression (Brown et al., 2006), and an increased incidence of STIs in people with borderline personality disorder (Chanen et al., 2007). Contrary to our hypothesis, we found no significant association between either the severity of symptomatology or clinical and demographic characteristics and high risk sexual behaviour. This suggests that sexual behaviour needs to be addressed across all mental healthcare services, rather than target young people with specific diagnoses or symptomatology.

Compared to a national sample of secondary school students, young people with mental health disorders tended to engage in high-risk sexual behavior at higher rates (Mitchell et al., 2014). A higher proportion of young people in this study had ever had sex compared 
to secondary school students (77\% vs 33.7\%, respectively) (Mitchell et al., 2014). Out of those who had been sexually active, $36.2 \%$ had more than three sexual partners in the last 12 months compared to $23.2 \%$ of secondary school students. Consistent condom use was higher in secondary school students than in young people in this study (43\% vs $36.3 \%$ comparatively) and STIs and rates of pregnancy were higher in the study sample compared to secondary school students.

\section{Clinical Implications}

These findings highlight the necessity for youth mental health services to address the sexual health of their clients. A framework for incorporating sexual health into a youth mental healthcare service has been trialed in Australia with headspace; however, it is yet to be expanded into wider use (Edwards et al., 2014). There are different methods by which the sexual health of young people could be addressed. First, the initial assessment of a young person presenting with a mental health disorder could include a discussion of sexual behaviour and sexual health, particularly in relation to STI testing, contraceptive use and pregnancy. It is possible that by routinely incorporating sexual health into the initial assessment, it may overcome the initial barrier that many young people face in discussing sexual health with their mental health provider. Second, youth mental health services could provide additional services on site, such as general practitioners or sexual health nurses, thereby providing a 'one stop shop'. Finally, mental health professionals 
could be 'upskilled' and receive training on how to identify high-risk sexual behaviour in young people with mental health disorders and facilitate and advise on screening, referrals and appropriate treatment if indicated. At a service level, it is important that the healthcare setting environment is inclusive to all young people and respectful to the diversity of gender and sexual identity.

\section{Strengths and Limitations}

These findings need to be considered within the limitation of the study. The study sample was self-selecting and there was no comparison group. Furthermore, the instrument we used relied upon self-report for contraceptive use, history of STIs, history of pregnancy and non-consensual sex, likely leading to an under-estimation of the actual rates of STIs, pregnancy and non-consensual sex, and a possible over-estimation of contraceptive use. There are a number of strengths to this study, such as the inclusion of young people affected by a range of mental health disorders and also diversity in regards to gender and sexual identity. The study also utilized well validated instruments for measurement of symptoms and the use of a questionaire from a school based survey, thereby allowing comparisons with this population.

\section{Conclusion}


The establishment of early intervention services and youth mental health services more broadly represents a unique opportunity to ensure that the sexual health of young people affected by mental health disorders is addressed. This study addresses some of the gaps in the literature and highlights the need for clinical pathways to address the sexual health of young people with mental health disorders.

\section{Acknowledgements}

No further acknowledgments to declare.

\section{Declaration of Conflicting Interests}

The Authors declare that there is no conflict of interest.

\section{Funding}

This work was supported with seed funding from North Western Mental Health. BO'D is supported by an early career fellowship with the NHMRC (1144300).

\section{References}

Agardh AA, Cantor-Graae EA and Östergren P-OA. (2012) Youth, Sexual Risk-Taking Behavior, and Mental Health: A Study of University Students in Uganda. International Journal of Behavioral Medicine 19: 208-216.

Bennett DL and Bauman A. (2000) Adolescent mental health and risky sexual behaviour : Young people need health care that covers psychological, sexual, and social areas. BMJ 321: 251-252.

Booth ML, Bernard D, Quine S, et al. (2004) Access to health care among Australian adolescents young people's perspectives and their sociodemographic distribution. Journal of Adolescent Health 34: 97-103. 
Brawner BM, Gomes MM, Jemmott LS, et al. (2012) Clinical Depression and HIV RiskRelated Sexual Behaviors Among African-American Adolescent Females: Unmasking the Numbers. AIDS Care 24: 618-625.

Brown A, Lubman DI and Paxton S. (2010) Sexual Risk Behaviour in Young People with First Episode Psychosis. Early Intervention in Psychiatry 4: 234-242.

Brown A, Yung A, Cosgrave E, et al. (2006) Depressed mood as a risk factor for unprotected sex in young people. Australasian Psychiatry 14: 310-312.

Buffardi AL, Thomas KK, Holmes KK, et al. (2008) Moving Upstream: Ecosocial and Psychosocial Correlates of Sexually Transmitted Infections Among Young Adults in the United States. American Journal Of Public Health 98: 1128-1136.

Chanen AM, Jovev M and Jackson HJ. (2007) Adaptive Functioning and Psychiatric Symptoms in Adolescents with Borderline Personality Disorder. The Journal of Clinical Psychiatry 68: 297-306.

Chanen AM, McCutcheon L and Kerr IB. (2014) HYPE: A Cognitive Analytic TherapyBased Prevention and Early Intervention Programme for Borderline Personality Disorder. Handbook of Borderline Personality Disorder in Children \& Adolescents: 361.

Cummings M and Melissa K. (2012) Youth health services: Improving access to primary care. Australian Family Physician 41: 339.

Donenberg GR and Pao M. (2005) Youths and HIV/AIDS: psychiatry's role in a changing epidemic. Journal of the American Academy of Child and Adolescent Psychiatry: 728.

Edwards CA, Britton ML, Jenkins L, et al. (2014) Including a Client Sexual Health Pathway in a National Youth Mental Health Early Intervention Service-Project Rationale and Implementation Strategy. Health Education Research 29: 354-359.

Elkington KS, Bauermeister JA and Zimmerman MA. (2010) Psychological Distress, Substance Use, and HIV/STI Risk Behaviors among Youth. Journal of youth and adolescence 39: 514-527.

Hedlund JL and Vieweg BW. (1980) The Brief Psychiatric Rating Scale (BPRS): A Comprehensive Review. Journal of Operational Psychiatry 2: 48-65.

Lehrer JA, Shrier LA, Gortmaker S, et al. (2006) Depressive Symptoms as a Longitudinal Predictor of Sexual Risk Behaviors Among US Middle and High School Students. Pediatrics 118: 189-200.

Leucht S, KAne JM, Kissling W, et al. (2005) Clinical implications of Brief Psychiatric Rating Scale scores. The British Journal of Psychiatry 187: 366-371.

McGorry PD, Edwards J, Mihalopoulos C, et al. (1996) EPPIC: an evolving system of early detection and optimal management. Schizophrenia Bulletin 22: 305-326.

Milnes A, Pegrum K, Nebe B, et al. (2011) Young Australians: Their Health and Wellbeing 2011. Canberra, Australian Institute of Health and Wellfare: Australian Institute of Health and Wellfare. 
Mitchell A, Patrick K, Heywood W, et al. (2014) National Survey of Australian Secondary Students and Sexual Health. ARCSHS Monograph Series No. 97. LaTrobe University, Melbourne, Australia: Australian Research Centre in Sex, Health and Society.

Ramrakha S, Caspi A, Dickson N, et al. (2000) Psychiatric Disorders and Risky Sexual Behaviour in Young Adulthood: Cross Sectional Study in Birth Cohort. BMJ 321: 263-266.

Rice SM, Halperin S, Cahill S, et al. (2017) The Youth Mood Clinic: an innovative service for the treatment of severe and complex depression. Australasian Psychiatry 25: 112-116.

Schuster R, Mermelstein R and Wakschlag L. (2013) Gender-Specific Relationships Between Depressive Symptoms, Marijuana Use, Parental Communication and Risky Sexual Behavior in Adolescence. Journal of Youth \& Adolescence 42: 1194-1209.

Shield H, Fairbrother G and Obmann H. (2005) Sexual Health Knowledge and Risk Behaviour in Young People with First Episode Psychosis. International Journal of Mental Health Nursing 14: 149-154.

Shrier LA, Harris SK, Sternberg M, et al. (2001) Associations of Depression, SelfEsteem, and Substance Use with Sexual Risk among Adolescents. Preventive Medicine 33: 179-189.

Smith L, Agius P, Mitchell A, et al. (2009) National Survey of Australian Secondary Students and Sexual Health ARCSHS Monograph Series No. 90. LaTrobe University, Melbourne, Australia: Australian Research Centre in Sex, Health and Society.

Stewart AJ, Theodore-Oklota C, Hadley W, et al. (2012) Mania Symptoms and HIV-Risk Behavior Among Adolescents in Mental Health Treatment. Journal of Clinical Child \& Adolescent Psychology 41: 803-810.

Turner AK, Latkin C, Sonenstein F, et al. (2011) Psychiatric Disorder Symptoms, Substance Use, and Sexual Risk Behavior Among African-American Out of School Youth. Drug and Alcohol Dependence 115: 67.

Yung AR, McGorry PD, Francey SM, et al. (2007) PACE: a specialised service for young people at risk of psychotic disorders. The Medical Journal Of Australia 187: S43-S46. 


\begin{tabular}{|c|c|c|}
\hline \multicolumn{3}{|l|}{ Table 1. Participant Characteristics } \\
\hline & $\underline{\mathrm{N}}$ & $\underline{\underline{0}}$ \\
\hline \multicolumn{3}{|l|}{ Gender } \\
\hline Female & 52 & 50.5 \\
\hline Male & 43 & 41.8 \\
\hline Transgender & 3 & 2.9 \\
\hline Non-binary & 3 & 2.9 \\
\hline Not sure & 2 & 1.9 \\
\hline \multicolumn{3}{|l|}{ Marital Status } \\
\hline Single & 64 & 63.4 \\
\hline In a relationship/married & 23 & 22.8 \\
\hline Living with someone as married & 7 & 6.9 \\
\hline Separated/Divorced & 7 & 6.9 \\
\hline \multicolumn{3}{|l|}{ Sexual identity } \\
\hline Heterosexual & 56 & 54.4 \\
\hline Bisexual & 26 & 25.2 \\
\hline Pansexual & 7 & 6.8 \\
\hline Homosexual & 5 & 4.9 \\
\hline Aromantic & 1 & 0.9 \\
\hline Not sure & 5 & 4.9 \\
\hline Other & 3 & 2.9 \\
\hline \multicolumn{3}{|l|}{ Country of birth } \\
\hline Australia & 84 & 81.6 \\
\hline Other & 19 & 18.4 \\
\hline Aboriginal or Torres Strait Islander & 4 & 3.9 \\
\hline \multicolumn{3}{|l|}{ Clinic } \\
\hline$\overline{\text { EPPIC }}$ & 54 & 52.4 \\
\hline PACE & 16 & 15.6 \\
\hline HYPE & 20 & 19.4 \\
\hline \multirow[t]{2}{*}{ YMC } & 13 & 12.6 \\
\hline & Mean & SD \\
\hline Age & 20.9 & 2.8 \\
\hline BPRS score $(168 \mathrm{max})$ & 47.7 & 12.2 \\
\hline
\end{tabular}

This article is protected by copyright. All rights reserved. 
$\mathrm{BPRS}=$ Brief Psychiatric Rating Scale

This article is protected by copyright. All rights reserved. 


\begin{tabular}{|c|c|c|c|c|}
\hline Clinic & EPPIC & PACE & YMC & HYPE \\
\hline \multirow[t]{2}{*}{ BPRS Score } & Mean (SD) & Mean (SD) & Mean (SD) & Mean $(\mathrm{SD})$ \\
\hline & $47.8(14.5)$ & $44.8(10.4)$ & $45.4(6.4)$ & $48.1(9.7)$ \\
\hline Primary diagnoses & $\mathrm{N}(\%)$ & $\mathrm{N}(\%)$ & $\mathrm{N}(\%)$ & $\mathrm{N}(\%)$ \\
\hline First Episode Psychosis* & $27(50.0)$ & & & \\
\hline Bipolar Disorder with Psychosis & $6(11.1)$ & & & \\
\hline Psychotic Disorder NOS & $6(11.1)$ & & & \\
\hline Schizophreniform disorder & $3(5.6)$ & & & \\
\hline Drug-induced psychosis & $3(5.6)$ & & & \\
\hline Schizophrenia & $2(3.8)$ & & & \\
\hline Delusional disorder & $2(3.8)$ & & & \\
\hline Schizoaffective disorder & $1(1.9)$ & & & \\
\hline $\begin{array}{l}\text { Depressive disorder with } \\
\text { psychosis }\end{array}$ & $4(7.4)$ & $8(50.0)$ & & \\
\hline Generalised Anxiety Disorder & & $2(12.5)$ & & \\
\hline Hypomania & & $2(12.5)$ & & \\
\hline $\begin{array}{l}\text { Schizotypal Personality } \\
\text { Disorder }\end{array}$ & & $1(6.3)$ & & \\
\hline No formal diagnosis & & $1(6.3)$ & & \\
\hline Bipolar Affective Disorder & & $2(12.5)$ & $3(23.1)$ & \\
\hline Major Depressive Disorder & & & $9(69.2)$ & \\
\hline Generalised Anxiety Disorder & & & $1(7.7)$ & \\
\hline Borderline Personality Disorder & & & & $20(100)$ \\
\hline \multicolumn{5}{|l|}{ Comorbid Diagnoses } \\
\hline Comorbid diagnoses present & $44(81.2)$ & $5(31.3)$ & $10(76.9)$ & $15(75.0)$ \\
\hline Generalised Anxiety Disorder & $5(9.3)$ & $4(25.0)$ & $8(61.5)$ & $9(45.0)$ \\
\hline Post-Traumatic Stress Disorder & $4(7.4)$ & $1(6.3)$ & $1(7.7)$ & $1(5.0)$ \\
\hline Major Depressive Disorder & $15(27.8)$ & $1(6.3)$ & & $13(65.0)$ \\
\hline Obsessive-Compulsive Disorder & $1(1.9)$ & $1(6.3)$ & & \\
\hline Social Anxiety Disorder & $3(5.6)$ & & & \\
\hline Gender Dysphoria & $1(1.9)$ & & & \\
\hline Panic Disorder & $1(1.9)$ & & & \\
\hline Bipolar Affective Disorder & $4(7.4)$ & & & $1(5.0)$ \\
\hline Autism Spectrum Disorder & $1(1.9)$ & & $1(7.7)$ & $1(5.0)$ \\
\hline Personality Disorder or Traits & $9(16.7)$ & & $1(7.7)$ & \\
\hline Anorexia Nervosa & & & $1(7.7)$ & \\
\hline Bulimia Nervosa & & & $1(7.7)$ & \\
\hline
\end{tabular}

This article is protected by copyright. All rights reserved. 


\begin{tabular}{|c|c|c|c|c|}
\hline Eating Disorder NOS & & & & $2(10.0)$ \\
\hline Adjustment Disorder & & & & $1(5.0)$ \\
\hline $\begin{array}{l}\text { Attention-Deficit Hyperactivity } \\
\text { Disorder }\end{array}$ & & & & $1(5.0)$ \\
\hline \multicolumn{5}{|l|}{ Comorbid Substance Abuse } \\
\hline $\begin{array}{l}\text { Substance Abuse Disorder } \\
\text { present }\end{array}$ & $20(37.0)$ & $3(18.8)$ & $5(38.5)$ & $5(25.0)$ \\
\hline Alcohol & $5(9.3)$ & $1(6.3)$ & $2(15.4)$ & $3(15.0)$ \\
\hline Cannabis & $16(29.6)$ & $1(6.3)$ & $3(23.1)$ & $2(10.0)$ \\
\hline Amphetamines & $12(22.2)$ & $1(6.3)$ & $1(7.7)$ & $2(10.0)$ \\
\hline
\end{tabular}




\begin{tabular}{|l|l|l|}
\hline \multicolumn{4}{|l|}{ Table 3. Sexual Behaviour in participants who had ever been sexually active (N=80) } \\
\hline & $\underline{\mathrm{N}}$ & $\underline{0}$ \\
\hline Sexual Activity & 51 & 63.8 \\
\hline Sexually active within last month & 48 & 61.5 \\
\hline Regular sexual partner in last 12 months & 29 & 36.2 \\
\hline$>3$ partners in last 12 months & & \\
\hline & & \\
\hline Communication & 39 & 48.8 \\
\hline Talked about pregnancy with previous sexual partner & 47 & 59.5 \\
\hline Talked about condom use with previous sexual partner & & \\
\hline Contraceptive use & 29 & 36.3 \\
\hline Consistent barrier contraception & 30 & 37.5 \\
\hline Consistent non-barrier contraception & 50 & 62.5 \\
\hline Consistent use any type of contraception & & \\
\hline & & \\
\hline Pregnancy & 21 & 26.3 \\
\hline Ever been pregnant (self or partner) & & \\
\hline & & \\
\hline Of those who reported pregnancy: & 20 & 95.2 \\
\hline Unplanned pregnancy & & \\
\hline Result & 5 & 23.8 \\
\hline Live birth & 6 & 28.6 \\
\hline Miscarriage & 9 & 42.8 \\
\hline Termination & 1 & 4.8 \\
\hline Not Reported & & \\
\hline & & 68.8 \\
\hline Sexually Transmitted Infections & 55 & \\
\hline Ever been tested & & \\
\hline
\end{tabular}

This article is protected by copyright. All rights reserved. 


\begin{tabular}{|l|l|l|}
\hline Ever tested positive & 14 & 25.5 \\
\hline Frequent drug use during sex & & \\
\hline Alcohol & 12 & 15.2 \\
\hline Cannabis & 12 & 15.2 \\
\hline Amphetamines & 7 & 8.9 \\
\hline Mean age of first sexual intercourse & $\underline{\text { Mean }}$ & $\underline{\text { SD }}$ \\
\hline & 16.5 & 1.9 \\
\hline
\end{tabular}

This article is protected by copyright. All rights reserved. 
Table 4. Comparison between general psychopathology and High-Risk Sexual Behaviour

\begin{tabular}{|l|l|l|l|}
\hline & BPRS & & \\
\hline & t-test & df & P \\
\hline Sexual Activity & & & \\
\hline Ever been sexually active & 0.86 & 101 & 0.48 \\
\hline Regular sexual partner in last 12 months & -0.31 & 99 & 0.73 \\
\hline$>3$ partners in last 12 months & 0.98 & 99 & 0.20 \\
\hline Sexually active within last month & -0.78 & 76 & 0.36 \\
\hline & & & \\
\hline Frequent drug during sex & & & \\
\hline Alcohol & 0.57 & 77 & 0.32 \\
\hline Cannabis & 0.62 & 77 & 0.97 \\
\hline Amphetamines & 1.04 & 77 & 0.12 \\
\hline & & & \\
\hline Contraceptive use & & & \\
\hline Consistent barrier contraception & -1.01 & 101 & 0.46 \\
\hline Consistent non-barrier contraception & -0.48 & 101 & 0.19 \\
\hline Consistent contraception (any form) & -1.06 & 101 & 0.99 \\
\hline & & & \\
\hline Pregnancy and STIs & & & \\
\hline Ever been pregnant (self or partner) & 0.92 & 84 & 0.66 \\
\hline Ever been tested & 0.75 & 84 & 0.49 \\
\hline Ever tested positive & 0.97 & 84 & 0.34 \\
\hline$*$ p $<0.003$ was taken as the level of significance when a Bonferroni correction was applied \\
\hline
\end{tabular}

This article is protected by copyright. All rights reserved. 


\begin{tabular}{|c|c|c|c|c|}
\hline & $\begin{array}{l}\text { History } \\
\text { non- } \\
\text { consensual } \\
\text { sex }\end{array}$ & $\begin{array}{l}\text { Comorbid } \\
\text { Substance } \\
\text { Abuse }\end{array}$ & Gender & $\begin{array}{l}\text { Sexual } \\
\text { Identity }\end{array}$ \\
\hline & $\mathrm{C}^{2}$ & $\mathrm{C}^{2}$ & $\mathrm{C}^{2}$ & $\mathrm{C}^{2}$ \\
\hline \multicolumn{5}{|l|}{ Sexual Activity } \\
\hline Ever been sexually active & 10.5 & 9.9 & 1.5 & 3.2 \\
\hline Regular sexual partner in last 12 months & 17.2 & 0.8 & 13.1 & 10.1 \\
\hline$>3$ partners in last 12 months & 10.2 & 6.7 & 3.8 & 16.3 \\
\hline Sexually active within last month & 9.0 & 1.2 & 20.3 & 3.2 \\
\hline \multicolumn{5}{|l|}{ Frequent drug use during sex } \\
\hline Alcohol & 1.1 & 4.5 & 0.16 & 17.1 \\
\hline Cannabis & 2.7 & 11.6 & 1.1 & 2.2 \\
\hline Amphetamines & 0.9 & 11.9 & 1.6 & 4.4 \\
\hline \multicolumn{5}{|l|}{ Communication with last partner } \\
\hline Talked about pregnancy & 12.4 & 3.3 & 7.3 & 45.8 \\
\hline Talked about condom use & 9.1 & 3.8 & 10.0 & 55.2 \\
\hline \multicolumn{5}{|l|}{ Contraceptive use } \\
\hline Consistent barrier contraception & 1.6 & 0.6 & 5.1 & 12.0 \\
\hline Consistent non-barrier contraception & 8.1 & 0.9 & 7.7 & 9.5 \\
\hline Consistent contraception (any form) & 4.9 & 0.05 & 9.1 & 13.4 \\
\hline \multicolumn{5}{|l|}{ Pregnancy and STIs } \\
\hline Ever been pregnant (self or partner) & 7.9 & 1.8 & 5.2 & 2.7 \\
\hline Ever been tested for STIs & 8.2 & 3.9 & 4.0 & 3.8 \\
\hline Ever tested positive for STIs & 7.9 & .07 & 2.5 & 4.2 \\
\hline
\end{tabular}

This article is protected by copyright. All rights reserved. 


\section{University Library}

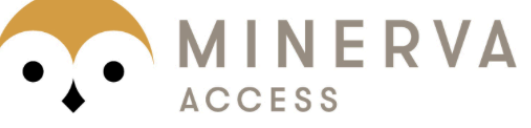

A gateway to Melbourne's research publications

Minerva Access is the Institutional Repository of The University of Melbourne

\section{Author/s:}

Sanchez, AYA;McMillan, E;Bhaduri, A;Pehlivan, N;Monson, K;Badcock, P;Thompson, K;Killackey, E;Chanen, A;O'Donoghue, B

Title:

High-risk sexual behaviour in young people with mental health disorders

Date:

2019-08-01

\section{Citation:}

Sanchez, A. Y. A., McMillan, E., Bhaduri, A., Pehlivan, N., Monson, K., Badcock, P., Thompson, K., Killackey, E., Chanen, A. \& O'Donoghue, B. (2019). High-risk sexual behaviour in young people with mental health disorders. EARLY INTERVENTION IN PSYCHIATRY, 13 (4), pp.867-873. https://doi.org/10.1111/eip.12688.

Persistent Link:

http://hdl.handle.net/11343/284186 